\title{
Biofunctionality of Probiotic Soy Yoghurt
}

\author{
Shilpa Vij ${ }^{1}$, Subrota Hati' ${ }^{2}$ Deepika Yadav ${ }^{2}$ \\ ${ }^{1}$ Senior Scientist, Dairy Microbiology Division, National Dairy Research Institute, Karnal, India; ${ }^{2}$ Research Scholar, Dairy Microbi- \\ ology Division, National Dairy Research Institute, Karnal, India. \\ Email: shilpavijn@yahoo.co.in
}

Received May $6^{\text {th }}$, 2011; revised June 28 ${ }^{\text {th }}$, 2011; accepted July $6^{\text {th }}, 2011$.

\begin{abstract}
Soybean provides health benefits such as reducing cardiovascular disease, reducing menopausal symptoms, weight loss, arthritis, diabetes, osteoporosis and brain function. It contains phytochemicals such as isoflavones, saponins and phytosterols that promote health benefits. Soy food products are perceived as healthy food and are considered an important part of the diet. More than 50\% consumers in the USA agreed that soy foods are healthy foods. Soymilk is considered as a suitable economical substitute for cow's milk and an ideal nutritional supplement for lactose-intolerant population and also considered cholesterol free product for cardiovascular disorders. Fermented soymilk is a good source of bioactive peptides such as anti-ACE, antioxidative, anti-cancer and immunomodulatory. Many fermented soy milk based products such as soy cheese, soymilk-kefir, soy yoghurt etc. are produced.
\end{abstract}

Keywords: Soymilk, Probiotic, Yoghurt, Bioactive Peptides

\section{Introduction}

Soybean, (Glycine max) (L) Merr. is economically the most important bean in the world, providing vegetable protein for millions of people and ingredients for hundreds of chemical products and a potential source of bioactive peptides [1]. On average, soybean contains about $40 \%$ protein [2]. Soy also contains carbohydrates, phytochemicals, saponins, phytic acid and fiber, all thought to provide health benefits. Phytochemicals include the isoflavones (genistein, daidzein and glycitein), phytic acid and saponins. Soy protein has been investigated for benefit in terms of other cardiovascular disease risk factors, reducing menopausal symptoms, weight loss, arthritis, brain function, and exercise performance enhancement. Saponins in Soy enhance immune function and bind to cholesterol to limit its absorption in the intestine [3].

Soymilk is considered as a suitable economical substitute for cow's milk and an ideal nutritional supplement for lactose-intolerant population [4]. It naturally has about the same amount of protein (though not the same amino acid profile) as cow's milk.

\section{Benefits of Soy Milk}

- Excellent source of protein and dietary fiber

- Has little saturated fat and no cholesterol and lactose

- Good source of iron
- Soy protein may reduce the risk of certain cancers, including breast cancer, prostate cancer, lung

- Dietary soybean increased plasma thyroxin, an advantage for areas with endemic goiter

- Has isoflavones, which deal with many health issues; most important being the prevention of various cancers, heart disease, osteoporosis, antioxidant etc.

- As it doesn't contain galactose, soy milk can safely replace breast milk in children with galactosemia

- Lacks casein and is a good source of lecithin and vitamin E

- Safe for people with lactose intolerance, or milk allergy

- It also helps in fighting the symptoms of menopause and in promoting eye health or anticatract

- It can conveniently be used as a weaning formula instead of cow's milk for infants

- It also shows antidiabetic and antiobesity property

\section{Fermented Soy Products}

Interest in fermented soybean products, such as natto, tempeh, soy sauce and soy paste, has grown in recent years. Fermentation is considered to be an efficient way to produce bioactive peptides. Many bioactive peptides have also been identified in fermented soymilk. For example, ACE-inhibitory peptides containing Ala, Phe and His have been isolated from soybeans fermented by $\mathrm{Ba}$ - 
cillus natto and chunggugjang fermented by Bacillus subtilis [5].

Fermentation improves the bioavailability of isoflavones, assists in digestion of protein, provides more soluble calcium, enhances intestinal health, and supports immune system. Both in soybean and nonfermented soy foods, isoflavones are found in concentrations ranging from 0.1 to $5 \mathrm{mg} / \mathrm{g}$ as biologically inactive glucoside conjugates, which comprise $80 \%$ to $95 \%$ of the isoflavone concentration. Glucoside isoflavones are very poorly absorbed in the small intestine compared with their aglycones because of their greater molecular weight and higher hydrophilicity. Furthermore, the glucosides are known to be less bioactive than their respective aglycones [6]. Probiotic lactic acid bacteria, when grown in soymilk, have the ability to bioconvert the glucoside isoflavones into their respective aglycones without the supplementation of any nutrition [7]. By soymilk fermentation, proteins are degraded into simpler form like oligopeptides and di, tri-peptides, thus relieving protein allergy problem and serve as good source of bioactive peptides. Calcium availability occurs at low $\mathrm{pH}$, so by fermenting soymilk and utilizing complex sugars present in it, calcium availability also increases. Also because of low $\mathrm{pH}$, harmful or pathogenic bacteria in the intestine get eliminated. Probiotic bacteria in fermented soymilk act as an immunogenic agent and enhance immune system.

\section{Biofunctional Properties of Fermented Soymilk}

Soybeans are initially soaked in water for overnight and soaked beans in required amount of water were ground with a commercial blender unit, filtered and boiled for 5 min [9]. Soymilk fermented,with Bifidobacterium significantly decreased the levels of total plasma cholesterol and very low-density lipoprotein (VLDL)+low-density lipoprotein (LDL)-cholesterol in rats [9]. Isoflavones in fermented soy yoghurt (aglycone-enriched) are absorbed more efficiently by rats than those in unfermented soy yoghurt (glucoside-enriched) [9]. Additionally, physiological effects of fermented soymilks are greater than those of unfermented ones [10] because of the greater bioavailability of aglycones themselves (Table 1). However, fermentation products (lactic acid and acetic acid) and probiotics (Bifidobacterium breve) can influence the absorption or metabolism of isoflavones. Similarly, organic acids enhance the absorption of calcium [11], and intestinal flora affect the absorption or metabolism of flavonoids [12].

\section{Soy Based Probiotic Yoghurt}

Soy fortified yoghurt is a nutraceutical food. Yoghurts with $5 \%$ added soy protein concentrate qualify for the FDA-approved soy health claim of "cholesterol reduceing" and also contain sufficient fiber to provide $1 \mathrm{~g}$ of dietary fiber per serving [13]. Soy yoghurt is fermented soy yoghurt made with a mixed starter culture consisting of Streptococcus thermophilus and Lactobacillus delbrueckii ssp. bulgaricus.

For a potential therapeutic effect, probiotic organisms need to be delivered in the active form. Dairy and soy foods may serve as the ideal systems for the delivery of probiotic bacteria to the human GIT, since they may provide a favorable environment, which promotes growth and enhances viability of these microorganisms. In dairy and soy applications, probiotic organisms are delivered with different fermented dairy and soy products, most notable yoghurt and soy yoghurt. Incorporation of probiotic organisms such as Lactobacillus acidophilus, Bifidobacterium $s p$. and $L$. casei in fermented products provides a potential to improve the quality of the product and the health status of consumers. Dairy and soy foods may serve as the ideal system for delivery of probiotic bacteria to the human gastrointestinal tract (GIT) due to provision of a favorable environment that promotes the

Table 1. Physiologically active peptide fragments from soybean storage protein [8]

\begin{tabular}{lll}
\hline & Peptide fragments & Protein source \\
\hline & VNPHQN & $\beta$-conglycinin \\
& LVNPHDHQN & $\beta$-conglycinin \\
& LLPHH & $\beta$-conglycinin \\
Antioxidant activities & LLPHHADADY & $\beta$-conglycinin \\
& VIPAGYP & $\beta$-conglycinin \\
& LQSGDALRVPSGTTYY & $\beta$-conglycinin \\
& FVIPAGY & $\alpha, \dot{\alpha}(\beta$-conglycinin subunit) \\
Inhibition of angiotensin-converting & ASUDTLI & $\alpha, \dot{\alpha}$ ( $\beta$-conglycinin subunit) \\
enzyme & DQTPRVI & A5A4B3 (glycinin subunit) \\
& YRILEF & $\dot{\alpha}(\beta$-conglycinin subunit) \\
Promoting action of phagocytosis & MITLAIPVNKPGR & $\dot{\alpha}(\beta$-conglycinin subunit) \\
& HCQRPR & A1aB1b (glycinin subunit) \\
& QRPR & A1aB1b (glycinin subunit) \\
\hline
\end{tabular}


growth and enhances the viability of these microorganisms. They play crucial roles in the fermentation of milk, soy and meat products, and vegetables such as cabbage.

During the bacterial fermentation, major constituents including lactose and milk proteins, soy proteins, raffinose, stachyose and other soy carbohydrates are utilized for the bacterial growth, which results in the conversion of fermentable materials into a range of products such as lactic acid, acetic acid, peptides, amino acids and different vitamins. In addition to exceptional nutritional attributes, milk and soy derived products such as fermented soy yoghurt or soy contain components that possess a range of different bioactive compounds. Compared to casein, soy protein showed a greater antioxidative ability in preventing lipid oxidation [14]. Isoflavones have been found to increase the activities of some antioxidative enzymes in the liver [15]. Some of these bioactive compounds are considered functional, thus making dairy and soy products important part of functional foods and nutraceuticals.

\subsection{Antihypertensive}

Hypertension is reported to affect $25 \%$ of the population (National Centre for Health Statistics). In the US alone, hypertension and its associated complications led to 35 million medical consultations in 2002 [16]. The annual drug costs associated with the treatment of hypertension and related diseases is estimated to be in the region of $\$ 15$ billion per annum in the US [17]. One of the most important intermediary factors for controlling hypertension is the action of the Angiotensin Converting Enzyme (ACE) [18]. Inhibition of Angiotensin I-Converting Enzyme (ACE) is considered a useful therapeutic approach in the treatment of high blood pressure in both diabetic and non-diabetic patients $[19,20]$. Several ACE inhibittory bioactive peptides have been found in enzyme hydrolysates of soy proteins. From fermentation of soybean containing medium with Bacillus natto or B. subtilis, several ACE inhibitory peptides, such as Val-AlaHis-Ile-Asn-Val-Gly-Lys or Tyr-Val-Trp-Lys, were isolated [21]. Fermented soy peptides from miso [22] and doenjang [23] have been shown to possess angiotensin-converting enzyme inhibitory activity and tripeptides (Val-Pro-Pro and Ile-Pro-Pro) from casein-added miso paste are reported to act as antihypertensive agents in spontaneously hypertensive rats. Peptides from soy are currently the subject of investigation for new drugs and functional food ingredients for gut health and modulating the intestinal absorption of nutrients. In soy yoghurt, the enhanced proteolytic activity by probiotic organisms as adjunct culture improved the production of ACE inhibittory compounds which exerted appreciable in vitro ACE inhibitory activity. The development of soy yoghurt con- taining higher concentration of released bioactive ACE inhibitors and viable probiotics may provide health benefits from these functional compounds more efficiently [24]

\subsection{Hypocholesterolemic}

Consumption of soy protein rather than animal protein significantly decreased serum concentrations of total cholesterol, LDL cholesterol and triglycerides without significantly affecting serum HDL cholesterol concentrations [25]. Studies in rats have demonstrated that SPI intake could modulate lipid and energy metabolism, including the synthesis and degradation of cholesterol [26]. Because of hypocholesterolemic effects shown by soy protein, Food and Drug Administration approved a health claim linking foods that are naturally rich in soy protein reduce coronary heart disease [27]. It has been showed that soy protein reduces circulating triglycerides and cholesterol in hypercholesterolemic individuals [28]. Soy protein can also shift LDL particle distribution to a less atherogenic pattern in an isoflavone independent manner [29]. Fermented soy yoghurt with bifidobacterium significantly decreased the levels of total plasma cholesterol, VLDL and LDL-cholesterol in rats [30]. Soy proteins also reduce blood cholesterol level and protect against cardiovascular disease. Soy isoflavones in soy yoghurt improves serum lipid profiles, vascular reactivity, and protection of LDL against oxidation.

\subsection{Antioxidative}

As antioxidants, genistein and daidzein protect cells from the damaging effects of free radicals that are known to promote ageing and to be involved in a number of disease states like atherosclerosis, joint (and other) inflamemation and diabetic complications. Soy yoghurt contains isoflavones (daidzein and genistein) which is having natural antioxidative property. For example, it has been shown that isoflavones have the potential to reduce the oxidation of low density lipoproteins (LDL) which is thought to be important in the prevention of vascular damage and disease. A study in Japanese men and women, found that soy isoflavone aglycones are better absorbed than their corresponding glucosides. The isoflavone aglycones in soy yoghurt are readily absorbed in the upper small intestine by passive diffusion, peaking in the blood within an hour of being ingested [31,32]. In contrast, the $\beta$-glucosides are not passively absorbed; however, they are easily hydrolyzed by $\beta$-glucosidases, either from intestinal bacteria, or an enzyme in the intestinal mucosa [33]. The 6''-O-malonyl- or 6''-O-acetyl-7-Ob-glucosides are poorly hydrolyzed by b-glucosidases and therefore enter the large bowel where the microorganism concentrations are much higher. In this more an- 
aerobic environment, not only hydrolysis occurs, but also reductive modifications to the heterocyclic ring producing dihydrodaidzein, O-desmethylangolensin and equol (7,4'-dihydroxyisoflavan). This study found that both genistein and daidzein were much better absorbed, with peak plasma concentrations almost 4 times higher, than were their glucoside counterparts [34]. Some of the observed effects of diets that are high in isoflavones will be outlined later. Free radicals and active oxygen species such as oxygen molecule behave as double-edge sword. They are important mediators in signal transduction and play important role in production of biologically active and essential compounds. At the same time; however, they are toxic and known to play a causative role in a variety of diseases. It has been demonstrated that soymilk-kefir possess significant antimutagenic and antioxidant activity and suggest that fermented soymilk may be considered among the more promising food components in terms of preventing mutagenic and oxidative damage. Kefiran is reported to possess antitumor activity [35]. It has also been observed that radical scavenging ability of soy peptides plays an important role in the suppression of lipid oxidation [36].

\subsection{Anticancer}

Anticancer activity of soy proteins has been suggested $[37,38]$. For example, soybean Kunitz trypsin inhibitor was reported to suppress ovarian cancer cell invasion by blocking urokinase up-regulation [39]. Another study showed that SPI diet altered colonic global gene expression profile and enhanced somatostatin, a known antiproliferative agent for colon cancer cells, and therefore would inhibit tumorigenesis [40]. Lifetime consumption of soy proteins in soy yoghurt reduced the incidence of azoxymethane induced colon tumors in rats [41]. Lunasin is a 43-amino acid bioactive peptide from soybean and other plant sources which is reported to possess antiinflammatory and anticancer properties [42]. Soy foods are rich in isoflavones, a major group of phytoestrogens that have been hypothesized to reduce the risk of breast cancer. Among women with breast cancer, soy food consumption was significantly associated with decreased risk of death and recurrence [43].

\subsection{Immunomodulatory}

Soybean peptides with immunomodulatory activities have been identified from soybean protein hydrolysates. For example, immunostimulating peptide preventing the alopecia induced by cancer chemotherapy has been isolated from an enzymatic digest of soybean protein [44]. Regarding the phagocytosis-stimulating activity, an active peptide sequence (MITLAIPVNKPGR) has been isolated from trypsin digests of soybean proteins [45].
Acid precipitated soybean protein fraction when digested with peptidase R displayed strong mitogenic activity \& increase number of interleukin, interferon, and CD4+ cells in mouse spleen cell. Soymilk when fermented with lactic acid bacteria shows enhanced immunomodulatory. Genistein is one of the most extensively studied isoflavones for its effect on immunity. A relatively high concentration of genistein inhibits lymphocyte proliferation response induced by mitogen or alloantigen in vitro [46, 47]. Genistein in soy yoghurt is known to be an inhibitor of protein tyrosine kinase, and its activity may contribute to the suppressive effect in vitro. Genistein induces doseresponsive reductions in thymic weight and size in OVX mice [48].Genistein decreases thymocyte numbers by up to $86 \%$ and doubles apoptosis. Genistein increased host resistance to B16F10 tumor and induced a dose dependent increase in cytotoxic T cell and NK cell activeties $[49,50]$. An in vivo study has shown that administration of daidzein increases the phagocytic response of peritoneal macrophages and the thymus weight in a dose dependent manner [51].

\subsection{Antidiabetic}

Metabolism of glucose is a complex process highly regulated by both peptides and steroid hormones and is influenced by diet [52]. Early studies in healthy human subjects showed that soy polysaccharides reduce postprandial glucose concentration suggesting that polysaccharides in soy may provide potential benefits in conditions of impaired glucose tolerance. Several studies reported increased insulin sensitivity (lower plasma and hepatic lipids, plasma glucose and plasma insulin concentrations) in rats fed isolated soy proteins compared with rats fed casein. A 37-kDa protein in soy appears to modulate insulin action on fat decomposition in vitro [53]. It has been suggested that soy isoflavones may be beneficial for diabetic subjects because of their estrogenic activity and their ability to prevent glucose-induced lipid peroxidation and inhibit intestinal glucose uptake by decreasing sodium-dependent glucose transporter, which results in a reduction in postprandial hyperglycemia. Estrogen is reportedly beneficial for preventing and treating type 2 diabetes by attenuating insulin resistance, improving insulin secretion and increasing $\beta$-cell mass [54]. Therefore, soy isoflavonoids may improve glucose homeostasis through estrogenic action. In addition, soy proteins may also improve glucose metabolism. Hence, soybeans may help prevent type 2 diabetes and delay its progression. In one study, soy protein induced a lower postprandial insulin-glucagon ratio in healthy and hypercholesterolemic subjects than casein. Soy proteins are rich in arginine and glycine, which are involved in insulin and glucagon secretion from the pancreas. Decreased 
plasma insulin by soy yoghurt may be due to decreased release from the pancreas or increased hepatic removal [55]. Thus, the decrease in cholesterol seen with soy protein in soy yoghurt may be due to the decreased insulin-glucagon ratio caused by arginine and glycine.

\subsection{Bone Health}

Isoflavones have bone-preserving properties that may be of potential value to reduce the risks of osteoporosis in postmenopausal women. In a study [56], it was shown in 66 menopausal women that the addition of isoflavones to soy protein, at a level of $90 \mathrm{mg} /$ day, resulted in a reducetion of bone loss in the lumbar spine, compared to placebo. In a study [57], it was shown that the consumption of soy isoflavones along with the diet prevented to a large extent the induced bone loss in OVX rats compared to sham operated rats. In another study, rats were given estradiol (estrogen) or genistein, the principal isoflavone in soy. Bone mass increased in both groups, demonstrateing that genistein has the same bone-building properties as estrogens [58]. Soya isoflavones in soy yoghurt have positive effects on bone tissue in controlled in vitro experiments on bone cell lines and animal studies and, as well as the first results from human studies, point to a promising future for soy isoflavones for the use in functional foods that target a reduction in the risks of osteoporosis.

\subsection{Antiobesity}

Obesity may lead to metabolic syndrome because it increases the prevalence of visceral obesity, insulin resistance, increased very low-density lipoprotein (VLDL) and low-density lipoprotein (LDL) cholesterol, decreased high-density lipoprotein (HDL) cholesterol, elevated triglycerides, hypertension (high blood pressure), and fatty liver, which are important factors of metabolic syndrome. Cholesterol synthesis in the liver is particularly stimulated by ingestion of saturated fatty acids and transfatty acids, whereas ingestion of monounsaturated fatty acids and polyunsaturated fatty acids (PUFAs) plays a beneficial role in health by lowering blood levels of triglycerides and VLDL and LDL cholesterol, thereby preventing insulin resistance [59]. Reduction of adipose tissue by isoflavones in vivo is caused by adipocyte apoptosis and reduction of individual adipocyte size. It has been reported that the dietary soy proteins also have role in reducing obesity [60]. It has been reported that genistein leads to a decrease in adipocyte size in juvenile ovariectomized mice, caused at least in part by decreases in LPL mRNA in adipose tissue [61]. Thus, similar to the effects of estrogen, the effects of genistein on adipose tissue could be due to an inhibition of the lipogenic LPL that regulates adipocyte lipid uptake. Others have re- ported that genistein and soy protein supplementation in soy yoghurt can decrease triglyceride, total cholesterol, and LDL cholesterol levels in the serum and liver of mice $[62,63]$. Furthermore, isoflavone supplementation has also been shown to effectively lower the serum cholesterol level in ovariectomized rats [64].

\subsection{Conclusions}

Soy yoghurt has many nutritional benefits including reducing cardiovascular disease, reducing menopausal symptoms, weight loss, arthritis and brain function. It contains phytochemicals such as isoflavones, saponins, phytosterols that promote health. Addition of probiotic culture enhances functional attribute of soy yoghurt. In future technological prospects that should be considered or addressed in view of the functionality of probiotic micro-organisms include: i) fermentation and drying technologies, and ii) microencapsulation. Furthermore, the probiotic dairy and soy industries should work closely not only with the regulatory authorities but also with the medical profession in order to substantiate the health claims associated with these beneficial micro-organisms. Overcoming these will help ensure the acceptability of probiotic dairy and soy products by the consumer and, hence, safeguard the future of the industry. In addition, more work is needed to develop a large-scale fractionation of protein hydrolysates to obtain products enriched with biologically active peptides of specific function that could be used as nutraceutical additives in functional foods.

\section{REFERENCES}

[1] R. J. Wynstra, "Intsoy Agenda: Expanding the Use of Soybeans," College of Agriculture, University of Illinois at Urbana, Champaign, 1986, p. 20.

[2] N. C. Nielsen, "Soybean Seed Composition,” In: D. P. S. Verma and R. C. Shoemaker, Eds., Soybean: Genetics, Molecular Biology and Biotechnology, CABI, Wallingford, 1996, pp. 127-163.

[3] T. Zind, "Making the Case for Soy," Food Processing, Vol. 25, No. 7, 1998, pp. 31-34.

[4] S. Dhananjay, S. Kulkarni, K. G. Kapanoor, V. K. Naganagouda and H. M. Veerappa, "Reduction of Flatus-Inducing Factors in Soymilk by Immobilized $\alpha$-Galactosidase," Biotechnology and Applied Biochemistry, Vol. 45, No. 2, 2006, pp. 51-57.

[5] H. Korhonen and A. Pihlanto, "Food-derived Bioactive Peptides-Opportunities for Designing Future Foods," Current Pharmaceutical Design, Vol. 9, No. 16, 2003, pp. 1297-1308. doi:10.2174/1381612033454892

[6] R. S. Muthyala, Y. H. Ju, S. L. D. Sheng and L. Williams, "Equol, a Natural Estrogenic Metabolite from Soy IsoflaOnes: Convenient Preparation and Resolution of R- and S-equolsand Their Differing Binding and Biological Ac- 
tivity through Estrogen Receptors Alpha and Beta,” Bioorganic and Medicine Chemistry, Vol. 12, No. 6, 2004, pp. 1559-1567. doi:10.1016/j.bmc.2003.11.035

[7] K. D. Setchell, C. Clerici, E. D. Lephart, S. J. Cole, C. Heenan and D. Castellani, "S-Equol a Potent Ligand for Estrogen Receptor Beta, is the Exclusive Enantiomeric form of the Soy Isoflavone Metabolite Produced by $\mathrm{Hu}-$ man Intestinal Bacterial Flora," The American Journal of Clinical Nutrition, Vol. 81, No. 5, 2005, pp. 1072-1079.

[8] D. Fukushima, "Recent Progress in Research and Technology on Soybeans," Food Science and Technology Research, Vol. 7, No. 1, 2001, pp. 8-16. doi:10.3136/fstr.7.8

[9] C. P. Champagne, J. Green-Johnson, Y. Raymond, J. Barrette and N. Buckley, "Selection of Probiotic Bacteria for the Fermentation of a Soy Beverage in Combination with Streptococcus thermophils," Food Research International, Vol. 42, No. 5-6, 2009, pp. 612-621. doi:10.1016/j.foodres.2008.12.018

[10] H. Kikuchi-Hayakawa, N. Onodera, S. Matsubara, E. Yasuda, O. Chonan, R. Takahashi and F. Ishikawa, "Effects of Soy Milk and Bifidobacterium Fermented Soy Milk on Lipid Metabolism in Aged Ovariectomized Rats," Bioscience, Biotechnology and Biochemistry, Vol. 62, No. 9, 1998, pp. 1688-1692. doi:10.1271/bbb.62.1688

[11] H. Sekizaki, R. Yokosawa, C. Chinen, H. Adachi and Y. Yamane, "Synthesis is Isoflavones and Their Attracting Activity to Aphanomyces Euteiches Zoospore," Biol Pharm Bull, Vol. 16, No. 7, 1993, pp. 698-701.

[12] H. Wei, L. Wei, K. Frenkel, R. Bowen and S. Barnes, "Inhibition of Tumor Promoter-Induced Hydrogen Peroxide Formation in Vitro and in Vivo by Genistein," Nutrition and Cancer, Vol. 20, 1993, pp. 1-12. doi:10.1080/01635589309514265

[13] S. Y. Lee, C. V. Morr and A. Seo, "Comparison of MilkBased and Soymilk-Based Yogurt," Journal of Food Science, Vol. 55, No. 2, 1990, pp. 532-536. doi:10.1111/j.1365-2621.1990.tb06803.x

[14] D. Fukushima, "Recent Progress in Research and Technology on Soybeans," Food Science and Technology Research, Vol. 7, No. 1, 2001, pp. 8-16. doi:10.3136/fstr.7.8

[15] D. K. Cherry and D. A. Woodwell, "National Ambulatory Medical Care Survey: 2000 Summary. Advanced Data from Vital and Health Statistics (No. 3282002),” National Center for Health, Statistics Hyattsville, MD, 2002.

[16] F. Ishikawa, "Probiotic Foods Expected to Prevent LifeStyle Derived Diseases," Healthist, Vol. 150, No. 69, 2002, pp. 69-76 (in Japanese).

[17] H. Kikuchi-Hayakawa, N. Onodera-Masuoka, M. Kano, S. Matsubara, E. Yasuda and F. Ishikawa, "Effect of Soy Milk and Bifidobacterium-Fermented Soy Milk on Plasma and Liver Lipids in Ovariectomized Syrian Hamsters," Journal of Nutritional Science and Vitaminology (Tokyo), Vol. 46, No. 2, 2000, pp. 105-108.

[18] M. Kishi, M. Fukaya, Y. Tsukamoto, T. Nagasawa and N. Nishizawa, "Enhancing Effect of Dietary Vinegar on the
Intestinal Absorption of Calcium in Ovariectomized Rats," Bioscience, Biotechnology and Biochemistry, Vol. 63, No. 5, 1999, pp. 905-910. doi:10.1271/bbb.63.905

[19] M. Tamura, K. Hirayama and K. Itoh, "Role of intestinal Flora on the Metabolism, Absorption and Biological Activity of Dietary flavonoids," Bioscience Microflora, Vol. 22, No. 4, 2003, pp. 125-131.

[20] S. Frantz, "Antihypertensive Treatments-ALLHATs off to the Golden Oldie," Nature Reviews Drug Discovery, Vol. 2, 2003, pp. 91-110. doi:10.1038/nrd1022

[21] B. Hernadez, P. J. Martin-Alvarez and E. Pueyo, “Assessment of Spectrophotometric Method for Determination of Angiotensin Converting Enzyme Activity: Influence of Inhibition Type," Journal of Agriculture and Food Chemistry, Vol. 51, No. 15, 2003, pp. 4175-4179. doi:10.1021/jf0341480

[22] E. D. Crook and S. Penumalee, "Therapeutic Controversies in Hypertension Management: Angiotensin Converting Enzyme (ACE) Inhibitors or Angiotensin Receptor Blockers in Diabetic Nephropathy? ACE Inhibitors," Ethnicity and Disease, Vol. 14, No. 4, 2004, pp. 1-4.

[23] J. Johnston, F. Volhard, "Renin-Angiotensin System: A Dual Tissue and Hormonal System for Cardiovascular Control,” Journal of Hypertension, Vol. 10, No. 7, 1992, pp. 13-26. doi:10.1097/00004872-199212000-00002

[24] A. Kimura, A. Takada, T. Okada and H. Yamada, "Microbial Manufacture of Angiotensin I-Converting Enzyme Inhibiting Peptides,” Koho 2000, JP 229996 A2 22, 2000, p. 11.

[25] K. Inoue, T. Gotou, H. Kitajima, S. Mizuno, T. Nakazawa and N. Yamamoto, "Release of Antihypertensive Peptides in Miso Paste during Its Fermentation, by the Addition of Casein," Journal of Bioscience and Bioengineering, Vol. 108, No. 2, 2009, pp. 111-115. doi:10.1016/j.jbiosc.2009.03.007

[26] S. H. Kim, Y. J. Lee and D. Y. Kwon, "Isolation of Angiotensin Converting Enzyme Inhibitor from Doenjang," Korean Journal of Food Science and Technology, Vol. 31, No. 31,1999, pp. 848-854.

[27] O. N. Donkor, A. Henriksson, T. Vasiljevic and N. P. Shah, "Rheological Properties and Sensory Characteristics of Set-Type Soy Yoghurt," Journal of Agricultural and Food Chemistry, Vol. 55, No. 24, 2007, pp. 98689876. doi:10.1021/jf071050r

[28] G. H. Anderson and S. E. Moore, "Dietary Proteins in the Regulation of Food Intake and Body Weight in Humans," Journal of Nutrition, Vol. 134, No. 4, 2004, pp. 974-979.

[29] N. Tachibana, I. Matsumoto, K. Fukui, S. Arai, H. Kato, K. Abe and K. Takamatsu, "Intake of Soy Protein Isolate Alters Hepatic Gene Expression in Rats,” Journal of Agriculture and Food Chemistry, Vol. 53, No. 10, 2005, pp. 4253-4257. doi:10.1021/jf0481103

[30] Y. Wang, P. J. Jones, L. M. Ausman and A. H. Lichtenstein, "Soy Protein Reduces Triglyceride Levels and Triglyceride Fatty Acid Fractional Synthesis Rate in Hypercholes-terolemic Subjects," Atherosclerosis, Vol. 173, No. 2, 2004, pp. 269-275. 
doi:10.1016/j.atherosclerosis.2003.12.015

[31] S. Desroches, J. F. Mauger, L. M. Ausman, A. H. Lichtenstein and B. Lamarche, "Soy Protein Favorably Affects LDL Size Independently of Isoflavones in Hypercholesterolemic Men and Women," Journal of Nutrition, Vol. 134, No. 3, 2004, pp. 574-579.

[32] H. Kikuchi-Hayakawa, H. Shibahara-Sone, K. Osada, N. Onodera-Masuoka, F. Ishikawa and M. Watanuki, "Lower Plasma Triglyceride Level in Syrian Hamsters Fed on Skim Milk. Fermented with Lactobacillus Casei Strain Shirota," Bioscience, Biotechnology and Biochemistry, Vol. 64, No. 3, 2000, pp. 466-475. doi:10.1271/bbb.64.466

[33] J. R. Liu, M. J. Chen and C. W. Lin, "Antimutagenic and Antioxidant Properties of Milk Kefir and Soymilk-Kefir," Journal of Agricultural and Food Chemistry, Vol. 53, No. 7, 2005, pp. 2467-2474. doi:10.1021/jf048934k

[34] R. A. King, J. L. Broadbent and R. J. Head, "Absorption and Excretion of the Soy Isoflavone Genistein in Rats," Journal of Nutrition, Vol. 126, No. 1, 1996, pp. 176-182.

[35] J. Sfakianos, L. Coward, M. Kirk and S. Barnes, "Intestinal Uptake and Biliary Excretion of the Isoflavone Genistein in the Rat," Journal of Nutrition, Vol. 127, No. 7, 1997, pp. 1260-1268.

[36] A. J. Day, F. J. Canada, J. C. Dı́az, P. A. Kroon, R. Mclauchlan, C. B. Faulds, G. W. Plumb, M. R. Morgan and G. Williamson, "Dietary Flavonoid and Isoflavone Glycosides are Hydrolysed by the Lactase Site of Lactase Phlorizin Hydrolase," FEBS Letters, Vol. 468, No. 2, 2000, pp. 166-170. doi:10.1016/S0014-5793(00)01211-4

[37] M. Shiomi, K. Sasaki, M. Murofushi and K. Aibara, "Anti-tumor Activity in Mice of Orally Adminstered Polysaccha-ride from Kefir Grain,” Japanese Journal of Medecine Science and Biology, Vol. 35, No. 2, 1982, pp. 75-80.

[38] E. Y. Park, H. Murakami, T. Mori and Y. Matsumura, "Effects of Protein and Peptide Addition on Lipid Oxidation in Powder Model System,” Journal of Agricultural and Food Chemistry, Vol. 53, No. 1, 2005, pp. 137-144. doi:10.1021/jf040221e

[39] W. H. Clair, P. Billings, J. Carew, C. Keller-McGandy, P. Newberne and A. R. Kennedy, "Suppression of DMH-Induced Carcinogenesis in Mice by Dietary Addition of the Bowman-Birk Protease Inhibitor," Cancer Research, Vol. 50, No. 3, 1990, pp. 580-586.

[40] M. Messina and S. Barnes, "The Role of Soy Products in Reducing the Risk of Cancer," Journal of the National Cancer Institute, Vol. 83, No. 8, 1991, pp. 541-546. doi:10.1093/jnci/83.8.541

[41] H. Kobayashi, M. Suzuki, N. Kanayama and T. Terao, “A Soybean Kunitz Trypsin Inhibitor Suppresses Ovarian Cancer Cell Invasion by Blocking Urokinase Upregulation," Clinical and Experimental Metastasis, Vol. 21, No. 2, 2004, pp. 159-166. doi:10.1023/B:CLIN.0000024751.73174.c2

[42] R. Xiao, T. M. Badger and F. A. Simmen, "Dietary Exposure to Soy or Whey Proteins Alters Colonic Global
Gene Expression Profiles during Rat Colon Tumorigenesis,” Molecular Cancer, Vol. 4, No. 1, 2005, pp. 12-19. doi:10.1186/1476-4598-4-1

[43] R. Hakkak, S. Korourian, M. J. Ronis, J. M. Johnston and T. M. Badger, "Soy Protein Isolate Consumption Protects against Azoxymethane-Induced Colon Tumors in Male Rats,” Cancer Letters, Vol. 166, No. 1, 2001, pp. 27-32. doi:10.1016/S0304-3835(01)00441-4

[44] P. Vermont, S. Torres, O. Ben and D. Mejia, "Presence of Lunasin in Plasma of Men after Soy Protein Consumption," Journal of Agricultural and Food Chemistry, Vol. 57, No. 4, 2009, pp. 1260-1266. doi:10.1021/jf803303k

[45] E. Shintaro and O. Hajime, "Characterization of a Cellular Immunostimulating Peptide from a Soybean Protein Fraction Digested with Peptidase R," Journal of Nutritional Science and Vitaminology, Vol. 55, No. 5, 2009, pp. 428-433. doi:10.3177/jnsv.55.428

[46] O. S. Xiao, Z. Ying, C. Hui, G. Kai, C. Zhi, Z. Wei and L. Wei, "Soy Food Intake and Breast Cancer Survival," The Journal of American Medical Association, Vol. 302, No. 22, 2009, pp. 2437-2443. doi:10.1001/jama.2009.1783

[47] T. Tsuruki, K. Takahata and M. Yoshikawa, "Anti-alopecia Mechanisms of Soymetide-4, an Immunostimulating Peptide Derived from Soy Conglycinin,” Peptides, Vol. 26, No. 5, 2005, pp. 707-11. doi:10.1016/j.peptides.2005.01.010

[48] F. T. Rapaport, T. Terashima, K. Tsukuda, K. Kono, T, Takayama and K. Malinowski, "Suppression of Lectin, Alloantigen, and Xenoantigen-Induced T-Cell Proliferation by Genistein,” Transplantation Proceedings, Vol. 29, No. 1, 1997, pp. 1261-1264. doi:10.1016/S0041-1345(96)00489-7

[49] M. Kogiso, T. Sakai and S. Yamamoto, "Genistein Suppresses Antigen Specific Immune Responses through Competition with $17 \beta$-Estradiol for Estrogen Receptors in Ovalbumin-Immunized BALB/c Mice,” Nutrition, Vol. 22, No. 7, 2006, pp. 802-809. doi:10.1016/i.nut.2006.04.003

[50] S. Yellayi, A. Naaz and P. S. Cooke, “The Phytoestrogen Genistein Induces Thymic and Immune Changes: a Human Health Concern," Proceedings of the National Academy Sciences of the United States of America, Vol. 99, No. 11, 2002, pp. 7616-7621. doi:10.1073/pnas.102650199

[51] I. R. Record, R. Head and A. L. Tonkin, "Genistein Inhibits Growth of B16 Melanoma Cells in Vivo and in Vitro and Promotes Differentiation in Vitro," International Journal of Cancer, Vol. 72, No. 5, 1997, pp. 860-864. doi:10.1002/(SICI)1097-0215(19970904)72:5<860::AIDIJC24>3.0.CO;2-B

[52] T. L. Guo, J. N. McCay and K. L. White, “Genistein Modulates Immune Responses and Increases Host Resistance to B16F10 Tumor in Adult Female B6CF1 Mice," Journal of Nutrition, Vol. 131, No. 12, 2001, pp. 32513258.

[53] E. Shintaro and O. Hajime, "Characterization of a Cellular Immunostimulating Peptide from a Soybean Protein 
Fraction Digested with Peptidase,” Journal of Nutritional Science and Vitaminology, Vol. 55, No. 5, 2009, pp. 428433.

[54] R. Zhang, Y. Li and W. Wang, "Enhancement of Immune Function in Mice Fed High Dose of Soy Daidzein,” Nutrition and Cancer, Vol. 29, No. 1, 1997, pp. 24-28. doi:10.1080/01635589709514597

[55] D. Y. Kwon, J. S. Jang, S. M. Hong, J. E. Lee, S. R. Sung, H. R. Park et al., "Long-Term Consumption of Fermented Soybean-Derived Chungkookjang Enhances Insulinotropic Action unlike Soybeans in 90\% Pancreatectomized Diabetic Rats," European Journal of Nutrition, Vol. 46, No. 1, 2007, pp. 44-52. doi:10.1007/s00394-006-0630-y

[56] A. E. Butler, J. Janson, S. Bonner-Weir, R. Ritzel and R. A. Rizza, "Beta-Cell Deficit and Increased Beta-cell Apoptosis in Humans with Type 2 Diabetes," Diabetes, Vol. 52, No. 1, 2003, pp. 102-110. doi:10.2337/diabetes.52.1.102

[57] S. B. Choi, J. S. Jang and S. Park, "Estrogen and Exercise may Enhance Beta-Cell Function and Mass via Insulin Receptor Substrate 2 Induction in Ovariectomized Diabetic Rats,” Endocrinology, Vol. 146, No. 1, 2005, pp. 4786-4794. doi:10.1210/en.2004-1653

[58] S. M. Potter, J. A. Baum, G. Teng and R. J. Stillman, "Soya Protein and Isoflavones: Their Effect on Blood Lipids and Bone Density in Postmenopausal Women," The American Journal of Clinical Nutrition, Vol. 68, No. 6, 1998, pp. 1366-1377.

[59] B. H. Arjmandi, R. Birnbaum and N. V. Goyal, "Bonesparing Effect of Soya Protein in Ovarian Hormone-Defi- cient Rats is Related to Its Isoflavone Content," The American Journal of Clinical Nutrition, Vol. 68, No. 6, 1998, pp. 1360-1365.

[60] J. J. B. Anderson, S. C. Garner, W. W. Ambrose and T. Ohue, "Genistein and Bone: Studies in Rat Models and Bone Cell Lines. Second International Symposium on the Role of Soya in Preventing and Treating Chronic Disease," Clinical Nutrition, Vol. 68, No. S1, 1996, pp. 1375-1379.

[61] S. D. Clarke, "Polyunsaturated Fatty Acid Regulation of Gene Transcription: A Mechanism to Improve Energy Balance and Insulin Resistance," Britain Journal of $\mathrm{Nu}$ trition, Vol. 83, No. 1, 2000, pp. 59-66. doi:10.1017/S0007114500000969

[62] M. T. Velasquez and S. J. Bhathena, "Role of Dietary Soy Protein in Obesity," International Journal of Medical Sciences, Vol. 4, No. 2, 2007, pp. 72-82.

[63] A. Naaz, S. Yellayi, M. A. Zakroczymski, D. Bunick, D. R. Doerge, D. B. Lubahn, W. G. Helferich and P. S. Cooke, "The Soy Isoflavone Genistein Decreases Adipose Deposition in Mice,” Endocrinology, Vol. 144, No. 8, 2003, pp. 3315-3320. doi:10.1210/en.2003-0076

[64] R. P. Patel, B. Boersma, J. H. Crawford, N. Hogg, M. Kirk, B. Kalyanaraman, D. Parks, S. Barnes and V. Darley-Usmar, "Antioxidant Mechanisms of Isoflavones in Lipid Systems: Paradoxical Effects of Peroxyl Radical Scavenging," Free Radical Biology and Medicine, Vol. 31, No. 12, 2001, pp. 1570-1581. doi:10.1016/S0891-5849(01)00737-7 